\title{
Honeybees, Communicative Order, and the Collapse of Ecosystems
}

\author{
Peter Harries-Jones
}

Received: 3 September 2008 / Accepted: 22 January 2009 /

Published online: 13 May 2009

(C) Springer Science + Business Media B.V. 2009

\begin{abstract}
The paper examines the sudden disappearance in the United States of millions of honeybees in managed bee colonies. The major research undertaken in the U.S. concentrates on finding the pathogens responsible. This paper suggests an alternative avenue of research a) that as a result of global warming there is a disjunction between bees pollinating cycles and the life cycle of plants b) that understanding changes in "timing cycles" as a result of global warming is the key to understanding the disappearance of the bees. It notes that Gregory Bateson argued that any condition of ecosystem collapse would be characterized first by a collapse in its communicative order rather, than from changed physical states. The collapse of bee colonies and demise of other pollinators is a seeming confirmation of Gregory Bateson argument. Honeybees are 'go betweens' in ecosystemic order. It also argues that an appropriate topology of timing cycles and their recursions would enable better visual comprehension of the heterarchical 'pattern which connects', in Bateson's phrase, and prompt awareness of possible catastrophe in human food supplies.
\end{abstract}

Keywords Communication · Honeybee-plant recursions · Sterile nectar · Go-betweens in ecosystems · Gregory Bateson · Don McNeil ·

Topology of timing cycles

\section{The Sudden Collapse of Managed Honeybees in North America ${ }^{1}$}

According to the U.S. Department of Agriculture (USDA), we are facing an "impending pollination crisis," in which both wild and managed pollinators, such as honeybees, are disappearing at alarming rates owing to habitat loss, pesticide

\footnotetext{
${ }^{1}$ This is a revised version of a paper first presented at the Semiotic Society of America Conference, "Semiotics and Survival," New Orleans, October, 4-7, 2007.

P. Harries-Jones $(\bowtie)$

Department of Anthropology, York University, Toronto, ON, Canada

e-mail: peterhj@yorku.ca
} 
poisoning, diseases and pests. The United States has already lost almost all its feral bees, anywhere from $80-95$ percent. This occurred by the year 1994, but is now occurring world wide. Currently the special concern of the USDA is with the sudden demise of managed bees. The demise has occurred almost exclusively among the producers of commercial honey in the United States in the last two or three years. The loss is approximately of one quarter of all managed honey bee colonies, one quarter of a little more than 2.1 million bee colonies, involving hundred of millions or perhaps over a billion individual bees. Managed bees produce honey. Yet they are also critical to other fruit and seed production; bees are crucial pollinators for California almond growers; for apples in Washington state; for squash in eastern states and much more. They have been regularly shipped from state to state to provide pollination services for many years (Public Broadcasting System 2007).

This year, in July 2007, the USDA regarded the situation as being a crisis of sufficient importance to release a comprehensive action plan in an attempt to resolve the matter (USDA 2007). On October 28th, 2007, and subsequently, a special programme shown on the Public Broadcasting System (PBS) in the United States, summarized the evidence from the USDA, together with the "Nature" programme's own research on the question, and came to the conclusion that the specific cause or causes that has led to the collapse of honeybee colonies in the United States, and to a lesser extent elsewhere, was still unknown (PBS 2007). According to this programme, earlier genomic research on bee pathogens had led to strong suspicions that a virus, Israeli Acute Paralytic Virus (IAPV), may be involved or IAPV with a number of other factors under the generic name of "stress" which has weakened the honeybees autoimmune system.

This paper will not attempt to rebut any of these findings. It will, however, switch attention from genomic results, to bee behaviour - especially honeybee behaviour in their interaction with plants. It will do so because the sudden collapse of managed bees has now drawn attention to a much wider problem, the crisis of population decline among many types of pollinators. Managed bees are an example of ecological 'go betweens' for many crops and flower gardens and the worldwide population decline of these 'go betweens' is of major concern. A variety of insects, birds, butterflies, bees and other living forms service over three-quarters of the one hundred staple crop plants that feed human kind - and $90 \%$ of all flowering plants in the world. Certain cultivated crops, particularly crops such as cashews, squash, mangos, cocoa, cranberries and blueberries, are at special risk. A count of these crops indicated that they are heavily pollinated by variety of bees, as well as $19 \%$ by flies, $6.5 \%$ by bats, $5 \%$ by wasps, $5 \%$ by beetles, $4 \%$ by birds, and $4 \%$ by butterflies and moths. For other crops it is reasonable to assume that this pattern is repeated with variation. In the US, bee pollination is estimated to be responsible for $\$ 15$ billion each year of crop value.

The thesis presented here is three-fold. First, studies of communicative interaction in an ecosystem context remain problematic in conventional scientific studies. While research in recent years has shown that all organisms are able to detect chemical signals in the environment and that the ubiquity of pheromones mediate a vast array of interactions, nevertheless, calling such interactions "communicative" still remains a most contentious issue. Some definitions of "communication" still insist that "true communication" be limited to signals within a species beneficial to the receiver Even 
in animal behaviour, the definition of communication is tied, more often than not, to patterns of behaviour "programmed to some extent by natural selection" and so biases study towards adaptive features most commonly associated with natural selection, namely reproduction and predator-prey relations (Wyatt, 2003:3ff).

Second, research on global climate change tends to concentrate on interactions arising from human activity, even indirect human activity, and its effects arising in the carbon cycle. This is not to deny general understanding that changes in natural ecosystems are among the first observable impacts of climate change. Thus, the timing of bird migrations and their alignment with timing of plant flowering dates (of which more below) are beginning to be widely recorded. Nevertheless, the pattern of research remains oriented toward the possible damaging effects of changes in the network of energy relations in an ecosystem (Patten and Higashi 1991; Grossman 2004) ${ }^{2}$ while communicative interactions in a systemic context - for example, the interactions of "go-between" species- is largely ignored. There are some good reasons for this lack of research. 'Fast reactions,' such as plant responses to change in the quality of light, are far more difficult to study than those changes which come more slowly over a much greater global space, as, for instance the melting of glaciers or ice cover in the Arctic (IPCC 2003:15, 16).

Yet the systemic context holds that communication not only contributes to the "self-organization" aspects of species interaction in ecosystems, bird-flowering plant interaction, but has a far larger role, that of sustaining life-cycles between species. This is the third point. As the influence of honeybees shows, all 'go- betweens' have a mutual causal influence which envelop their own life cycle, plant life cycles, and, ultimately, our own human cycles of life. Their influence is not only mutual causal at their own level of order, but reaches over multiple levels of biological order. Any dramatic declines of honeybees, and other 'go-betweens' who perform fertilization of fruits, vegetables and edible tree products, would indeed cause wide scale food crop and ecosystem collapse long before humanity felt the full force of global warming, even runaway global warning. Their sudden disappearance for whatever reason brings this unsettling possibility to the fore. To support a conceptual understanding of this ecosystemic view, I look briefly at Gregory Bateson's understanding of why the focus of our attention should always be the organism plus environment in circular, or recursive, activity, and to natural timing cycles as an ordering link between bioenergy, communication and multiple levels of biological order.

\section{The U.S. Department of Agriculture Assessment}

Currently, no one knows what is causing the managed bees to perish. Those researching the sudden decrease in adult managed bee populations are mystified by the way in which the sudden population decrease has occurred. Millions of adult bees have simply vanished. Dead bees are nowhere to be found - neither in nor

\footnotetext{
$\overline{{ }^{2} \text { In 2004, a Scientific American }}$ article on Alastair Fitter's pioneering study of changes plant flowering and how it might relate to bird migration noted that Fitter's research was among "a small group of studies [which] is taking up the challenges of looking into whether global warming is having an adverse effect on the relations among plants and animals within ecosystems" (Grossman 2004).
} 
anywhere close to the hives. Bees that are left in the hive are sick with a variety of diseases and brood bees, doomed offspring, are without food. Researchers have come to call the mysterious phenomenon "Colony Collapse Disorder" (CCD). Normally, nearby bee populations or parasites would raid the honey and pollen stores of deserted colonies (for example, if a bee colony dies through being exposed to excessive cold). In this case bees and other insects leave the abandoned hives untouched. Another surprise is that the queen bee has sometimes been found external to the hive, which suggests that there is something in the colony itself which is repelling the re-entry of the bees.

The following are the main causative agents either suggested to or investigated by the USDA (see Figure below): varroa mites, which have been known to destroy colonies in the past; fungus; new forms of pesticides; genetically modified (GM) crops; immunodeficiencies; 'stress' through constant long distance transportation of bees, other beekeeping practices such as the frequent use of antibiotics; global warming. In addition, one causative agent that caught media attention was that managed bees were being exposed to new forms of electromagnetic radiation particularly to use of mobile phones. The USDA also observed that an interesting causative agent might be malnutrition, and I will return to this observation in some detail below.

\section{USDA: Questions and Answers: Colony Collapse Disorder (CCD).}

No common environmental chemicals or pathogens stand out as the causative agent Three major possibilities:

1. Pesticides may be having unexpected negative effects on honey bees.

2. A new parasite or pathogen may be attacking honey bees. One possible candidate being looked at is a pathogenic gut microbe called Nosema. Viruses and mites are also suspected, one possible source being Israeli Acute Paralysis Virus.

3. A perfect storm of existing stresses may have unexpectedly weakened colonies leading to collapse. Stress, in general, compromises the immune system of bees.

**stresses could include infection by the varroa mite; poor nutrition due to apiary overcrowding; pollination of crops with low nutritional value, or pollen or nectar scarcity; exposure to limited water supplies; migratory stress brought about by increased needs for pollination.

The researchers of the USDA have concluded a) use of mobile phones near bee colonies seems to be the most unlikely cause. b) The presence of varroa mites, and planting of GM crops do not appear consistent with the overall incidence of CCD - a least as a direct cause of death in the short term. Neither can be ruled out as a contributory factor, however. The planting of GM crops seems to have disturbed the ranging patterns of honeybees. c) Evidence of almost all known bee viruses was widespread in the few surviving bees of a collapsed colony. Some had five or six infections at the same time and were infested with fungi - a sign, experts say, that the insects' immune system may have collapsed. Yet this latter evidence is not conclusive for the bees that have left the hive. One new type of pesticide is of widespread concern, a nicotine-based pesticide, imidacloprid. The known effects of imacloprid on termites include apparent failure of the immune system and disorientation. The effects of sub-lethal doses on honeybees have been documented to affect homing and foraging activity, including impairing communication and 
learning performance. In France, where they have already banned the use of this pesticide, researchers refer to this condition as "mad bee disease.",

Note that all of this research presumed direct effects of either a) or b) or c) or d) on the bee population, with some researchers opting for a combination of effects, a "one-two punch" as they put it. More significant for purposes of this paper is that the attempt to derive causation concentrates almost entirely on honeybee pathogens and not on bees in their more normal interactive environment with plants. Of course, researchers have contemplated the wider domain of bee behaviour, especially with regard to evidence of malnutrition. Since managed honeybees are trucked from site to site to perform their services of fertilization, if the crop which they are servicing undergoes drought conditions, then nectar flows, crucial for honeybee nutrition and reproduction, will undoubtably suffer. This happened with the bees servicing California almond trees in the last couple of years.

Yet there is not sufficient evidence about plant pollen and nectar flows in current data-bases to sustain a wider examination of the malnutrition factor. As a result any tracking of the relation between bee malnutrition and environmental changes has been minimal compared to research on bee pathogens. From my own experience, I know that those who manage bees are perfectly willing to confirm possibilities of global climate change affecting bee populations, since the condition of any source of sugar and/or nectar dominates honeybee behaviour, but without the existence of such a database of nectar flow, their evidence is regarded as anecdotal.

\section{Malnutrition and Auto-immune Deficiency}

Given that no common environmental agents or chemicals stand out as being definitively causative, it would surely be reasonable to examine propositions about bee interaction with plants, in order to account for the most likely cause for the massive disappearance of adult bees. At minimum, discussion about interaction with plants offers a means to re-contextualize notions of honeybee 'stress.' When Karl von Frisch published his papers on the wagging dance of bees, he opened up a whole scientific realm of communication among non-human organisms which won him a Nobel Prize. To step into von Frisch evidence is to step into the realm of a different sort of science, one which gives a deal of credence to the wealth of communicative activity that is displayed in any ecosystem, and, as a corollary, the ways in which communicative responses on the part of living organisms in ecosystems sustain their self-organization (von Frisch 1967). It leads on, as a matter of course, Humberto Maturana's definition of “autopoiesis” (Maturana and Varela 1998):

... the basic consequence of the autopoietic organization is that everything that takes place in an autopoietic system is subordinated to the realization of its autopoiesis, otherwise it disintegrates.

\footnotetext{
${ }^{3}$ There is some doubt whether the European examples of the phenomenon can be called CCD or not, for there are wide differences between the size of population decline in the U.S. and in Europe. For example if "mad bee disease" and CCD is the same phenomenon, the population effects of "mad bee disease" is very much lower in Germany (only 0.06 percent) than colony collapse ( $25 \%$ of all bee colonies in the U.S.).
} 
Along with this emphasis on self-organization comes an understanding that communication involves not merely the "sending" or "receiving" of messages but response and interpretation as well. Thomas Sebeok, who established the science of zoosemiotics in North America, argued : "Semiosis [communication, response, its interpretation, and meaning] is, in fact, the instrument which assures the maintenance of the steady state of any living entity" (Sebeok 1985). So a first step, if one comes from a zoosemiotic background, would be to link communicative and interpretative activity associated with the disappearance of bees to food resources and to life-cycles.

By contrast, one has to dig deep down into the USDA literature to find any connection linking malnutrition to a possible cause of CCD. As the USDA admits, honeybees rely on pollen for protein, vitamins, fats and minerals, and in a typical year managed bees can always find enough mix of pollens, their "health food," to meet their dietary needs and get them through a normal life cycle. The pollen that they bring back to the hive is also food for the brooding bees, the next generation.

One could argue that the evidence the USDA cites is not strong enough. Intergenerational life cycles could clearly be the most significant factor in the whole phenomenon of CCD and bee disappearance. In the summer, worker bees go through a six-week life cycle: some weeks inside the hive, three outside it as foragers. After about 30 days as foragers they die of old age. As Eric Masson, a researcher who favours the malnutrition hypothesis, put it (Berger 2007):

When bees are coming to the end of their life for whatever reason, they just fly off and don't come back. They fly out to die because flying out and dying is what they do.

Moving into fall, the colony rears bees that have a long life expectancy - from about October to March of the next year. Why would these bees fly off and disappear? The behaviour of the winter bees flying out and not carrying through their proper adult life-cycle is difficult to explain unless the winter bees of the brooding colony are not getting enough food. The link, Masson explains, is that summer bees may seem to be foraging adequately, and beekeepers observing their summer bees bringing pollen back to the brood in the hive may assume that all is well. Yet the beekeepers cannot know if the pollen grains that the bees bring back have any nutrition in them. So any beekeeper would be surprised if the bees in their colony, which seemingly have plenty of pollen, suddenly disappear.

Following this line of reasoning, the next question is why is the pollen sterile? One source of suspicion clearly falls on global climate change, but at this point, evidence about the chain of causation in the USDA studies begins to disappear. It is known that a blast of hot temperature about the time the flower buds are forming and the pollen grains are beginning to form can yield sterile pollen. It should be possible to match local records of increased temperatures and reduced rainfall as a result of global climate change to the issue at hand. It is also known that there has been considerable change in environmental circumstances affecting the short life cycle of summer bees. Yet according to one beekeeper, Wayne Esias, who has sought information on this very point, records do not exist for detailed examination. He himself has kept rigorous records over a long period of time, though publicly he 
admits that his evidence is anecdotal. His records show that pollen and nectar flow comes almost a month earlier in the Baltimore areas than it did in the 1970s. In Esias opinion, ecologists undertaking research of climate change ecologists have been mainly concerned with carbon cycling and the relation between increased $\mathrm{CO} 2$ and plants and have not paid sufficient attention to the timing of blooming and nectar availability and quality of pollen.

Esias, says (Berger 2007):

I tried to find out how temperatures would affect blooming dates, and there is virtually no information in the literature on how temperature affects blooming dates of our trees and how increased $\mathrm{CO} 2$ concentrations affect blooming dates.... There's lots of research that says it makes plants grow faster, and some of them, like poison ivy, become more toxic... [but] without information about when the plants bloom and how the quality of the flora changes, we are in a poor position to assess [bee response to] the effect of changes in temperature and rainfall on our ecosystems.

Subsequent to Esias comments, the IPCC Synthesis Report on climate change was released in October-November 2007. The 2007 findings from the Intergovernmental Panel on Climate Change, IPCC, would halve Esias estimate, although their figures on rate of change are inconsistent. Nevertheless, the Report verifies what Esias says, that timing and duration of the pollen season have been found to be affected by regional warming (IPCC Report AR4, Working Group II, 2007:103). The IPCC report also concurs that research covering eco- systemic interrelations between insects and plants, predators and prey, in the light of significant blooming changes, has not yet been undertaken. It notes a sudden revival in the science of "phenology," a natural science activity in the nineteenth century established to record first days of blooming and other recurrent life-cycle or recursive events. There is no discussion in the Report on nectar availability, quality of pollen or on the gap in flowering times resulting in pollinators collecting sterile pollen.

\section{Communicative Order and Ecosystem Collapse}

The dynamics of communication in ecosystems has advanced greatly in recent years compared to the times of Sebeok and other lone voices in zoosemiotics. Today there are a segment of botanists who no longer regard plants as mechanistic robots and have been publishing a range of highly significant articles on plant communication (Baluska et al. 2006), and there is a segment of molecular biologists in the field of biosemiotics and ecosemiotics who wish to extend redraw the whole understanding of "information" in the organic cell and studies of DNA and RNA. The latter advance the notion of a communication and interpretation embracing all of living organisms and pose a conceptual order of a semiosphere, a field of communication and meaning which they believe to be as enveloping as the biosphere as an arena for scientific investigation (Hoffmeyer 1996).

One progenitor of both biosemiotics and ecosemiotics was Gregory Bateson, a biologist and anthropologist who, from the end of the Second World War, advanced the study of patterns of communication in cybernetics, in social order (specifically 
family therapy) and, towards the end of his life, tied his discussion to communicative order in ecosystems (Hoffmeyer 2008a, b). The principle employed in Bateson's study of ecosystems is that information in any communicative relation triggers living organisms' response to changes in other interrelations affected by change, so that what the biologist might call adaptation, was more of a series of circular responses to responses circulating through an ecosystem in non-linear manner than a direct outcome of input-output forces of energy and biomass. Bateson also argued that it was neither the living organism alone, nor the environment alone that should become the focus of our attention, but rather that the organism plus environment in circular, or recursive, activity. Bateson's writing offers a contrary view to accepted conventions in natural science, in fact he reverses one of natural science accepted dogmas. The discussion of living systems as both self-referring, and mutually implicating is perfectly normal science, he argues; when an organism is depicted as responding to physical forces alone, the scientific paradigm begins to verge on a mystical view of nature (Harries-Jones 1995).

Bateson's is quite clear that ecosystems do not live by the biophysical requirements of energy and biomass alone. Because ecosystems are ordered, and because that ordering occurs through the activity of living organisms that contribute to such order, those organisms cannot be perceived to be 'mindless' or unable to respond to information flow. His view was a) that ecosystems are built up through communicative interaction on the part of organisms that compose it b) physical aspects of ecological organization are highly responsive to change in information interactions because c) change of information triggers change in physical states. Bateson also proposes that ecosystem organization is meaningful to the organisms that participate in it, that is to say, they are able in some manner to interpret the conditions of their own existence. Thus, the array of communicative interactions among and between the organisms that compose it are equally significant to the array of biophysical interactions within the ecosystem. Human beings are not the sole organisms affecting the physical composition of ecosystems.

Bateson included plants in his observations about communicative activity. With regard to plants, there were some important restrictions which characterize a difference between plant 'communication' and that of higher order animal responses or human responses to information. Plants only receive command or injunctive type of information, that is to say information about restraint or release. They are able to make intelligent responses to change, for they have to undertake response to change in order to survive. But they have no ability to engage in the sort of information used by animals and insects that move around. This has led human beings to assume that they were robotic. Yet it would be a mistake to assume total absence of communication and learning in the plant world, as if all communication and learning in the living world requires precisely the same types of senses, together with sensory information as applies in the human world.

Bateson noted that a plant meadow of mixed species has a multiplicity of species is unendingly bumped by information, information with news of contrast and change. Such a meadow is characterized by a dynamic pattern. The dynamic pattern of the meadow or field acts as a sort of unlocalized sense organ, best represented by the metaphor of a dance: "a sort of dance, rather formal, say a minuet" and the formality of "the dance" [in response to change in light] is there to detect and to classify other patterns of the dance. (Bateson and Bateson 1987:198) 
Bateson spoke only of system responses and did not make any assumption about individuation in plant response. He held that there was no direct mapping of signal transduction from environment to plant, even in the case of their response to light. Plants are, of course, peculiarly sensitive to light - and plants sense change. Their response is expressed in the organism as restraint or release. Yet this aspect of their response, restraint and release, is not equivalent to an automatic on-off button. Rather plants sense "difference". They scan in order to sense difference. "Difference" is neither in the outside world nor solely in the inside world, but is created by an act of comparison. This act, scanning, is an event in time sufficient for the plant to determine any difference which makes a difference for it. How much of this "information" is specific for the individual plant, rather than for the whole complex of multiple species of plants is open to question (Bateson and Bateson 1987:198).

Most important for the present discussion is the fact that Bateson, in his commentary on communicative activities in ecosystems, argues that information can trigger systemic degradation of energy without itself being a component part of energetic input-out, much like a thermostat in a mechanistic system (Bateson 2000). Thus the first sign of ecosystem collapse would be characterized by a collapse in its communicative order rather than from its changed physical state. He stated that it is more likely that communicative interaction among and between organisms in an ecosystem will breakdown as a result of too much fragmentation in their complex feedbacks, before physical degradation of the ecosystem occurs. This means that we should pay the closest attention to any systemic changes of information in an ecosystem and its recursive properties i.e. change in the feedback responses of living organisms to each other, and how that change is registered by living organisms.

\section{Collapsed Seasonal Disorder as Collapsed Seasonal Timing Cycles}

Bateson did not offer a detailed example of an ecosystem collapse, but CCD threatens to provide such an example. Another title for Colony Collapse Disorder would be Collapsed Seasonal Disorder, a disorder initiated by global warming and characterized by disjunction in "timing cycles." In the case of insects and plants, loops of mutual activity are themselves looped to seasonal cycles. Rapid climate change has resulted in disjunction of a series of cycles including a) seasonal cycle change in flowering among plants, b) bees pollination collection cycles among plants c) life-cycle of bee reproduction in the hive. These mutual activity loops are only the most evident cycles. If we regard these loops extending into ecosemiosis, it would be quite reasonable to assume that when foraging yields sterile pollen, it initiates sufficient stress or nutritional deficit to alter behaviour. Certainly bees require looped dynamics between them and plants activity and, jointly together, in seasonal dynamics.

Though both plants and bees can adjust to change, they require relatively invariant timing to maintain persistence of these activities. If the Baltimore case is indicative, the disjunction in timing-cycles, and the resultant shift in seasonal pollen and nectar flow - coming almost a month earlier than they did in the 1970s - is a major change of conditions which would indeed alter life- cycle circumstances in a 
drastic manner. The changes must create conditions which the participants of the life-cycle, bees, both worker bees returning to he hive and brooding bees inside the hive both feel, and interpret. Equally, the brooding generation both feels and perceives the lack of nutrition in sterile pollen. Winter bees then respond by flying out. This honeybee activity is habituated - flying out and dying in their search for sugar and nectar is what they do.

\section{A Topology for Visualizing Timing Circles}

As indicated above, ecosystem ecology is overwhelmed by analyses of energy flows, though its network topologies usually register space and/or -time variations in statistical patterns (Patten and Higashi 1991). These studies usually evoke a highly abstract pattern of causality, usually quantitative assessments. The introduction of communication into ecosystem activity makes appraisal far more complex, since communication is coordinative for the ecosystem as a whole, and is therefore both mutual causal and multi-level. No wonder an ecosystem communicative phenomena like Colony Collapse Disorder cannot be satisfactorily explained though any singlefactor models. Rather, understanding changes in "timing cycles" as a result of global warming is the key to understanding the disappearance of the bees.

A mutual causal, multi- level approach begins with an examination of cycles that relate change in the flux of bioenergy to seasonal timing coordinates to communication patterns coordinating interaction among plants, animals and humans. However, the depiction of these mutual causal multi-level feedbacks loops has proved elusive. Two well known ecologists made a start in this direction a few years ago when they suggested that the circularities of "timing circles" in ecology (recursive cycles) could be linked to the study of scale in biological order. Originally, their suggestions were made almost as an aside. They noted that "timing circles in ecology look like a series of overlapping bagels or donuts" (Allen and Hoekstra 1992). They unfolded this compressed statement, revealing interesting reasons for the 'bagel' formation, for these bagels are, in fact a series of toruses or toroidal forms. They also suggested that the way these timing circles or 'bagels' overlapped with one another was not haphazard, but created ecological "structures." Their presentation of ecological structures shows how each timing circle may move through many different "structures," and, similarly how the "structures" are composed of many different timing circles. They went no further in examining the full implications of their non-orientable topology.

More recently Don McNeil has generalized Allen and Hoekstra's discussion of structure in timing cycles, showing that the structure of timing cycles is best characterized as 'relative invariance' (McNeil 2004, 2007). Relative invariance marks organizational process in any circular or recursive phenomena; it is the "goings on" within such systems. McNeil's toroidal maps present a reversal in focus from studies of mechanistic systems . Energy throughput, the usual prime focus in mechanistic systems, represents only 15 per cent of the formal characteristics of any topology of "relative invariance," whereas circularities (recursive loops) represent 85 per cent of their other formal characteristics. This major reversal in visualization of multilevel ecosystem features and helps enormously in bringing the abstract notions of the circular, its rhythms and its recursions to concrete attention. 
From a percipient's viewpoint, timing cycles operate in a manner that is in some ways inverse to the concept of "time" used in statistical procedures. In the latter, "time" is an attributed quantity by the observer. But when recursions manifest themselves in living systems, timing or frequency is the 'real' relation to all other relations or connections in the model produced. And 'real' relations, or frequencies that is pulses, rate, rhythms, resonances, associated with life-cycles -can best be captured and mapped on a torus. Other aspects of McNeil's torus fit admirably with a depiction of communicative events in Biosemiotics. The torus is heterarchical in form, thus fulfilling one of Bateson's primary conditions; it displays "relative being," a condition that Hoffmeyer argues is fundamental to semiosis (Hoffmeyer 2008a, b). As a heterarchical form it enables displays of cross-over events such as analogue and digital coding duality, or cross-over of biophysical and ecosemiotic events, one set of events depicted in the meridial cycles of a torus and the other in the annular cycles of a torus. ${ }^{4}$

\section{Conclusion}

This article has examined conceptual, empirical and methodological approaches to communication in ecosystems, communication unequivocally defined as semiotic at several levels of ecosystem organization. Conceptually, Bateson argued that information can trigger systemic degradation of energy without itself being a component part of energetic input-out, much like a thermostat in a mechanistic system. Thus the first sign of ecosystem collapse would be characterized by a collapse in its communicative order rather than from its changed physical state. He stated that it is more likely that communicative interaction among and between organisms in an ecosystem will breakdown as a result of too much fragmentation in their complex feedbacks, before physical degradation of the ecosystem occurs. Empirically, his argument seems to be supported by the sudden disappearance of bee colonies, especially among industrially managed honeybees, known as Collapsed Colony Disorder. Current attempts to pinpoint causes for colony collapse disorder have concentrated almost entirely on trying to isolate honeybee pathogens and not on bees in their more normal interactive environment with plants. Illustrated here is a good example of the forgotten role of communication in maintaining coordinated organization in ecosystems, not only sustaining life within a species but, more influentially, sustaining life-cycles between species. In the case of honeybees, their influence as 'go betweens' envelop their own life cycle, plant life cycles, and, ultimately our own human cycles of life. So far as method is concerned, visual representation of mutual causal, multi-level events like Colony Collapse Disorder has been lagging. I suggest that a topology of 'real' feedback loops is possible to display through the medium of a torus, itself a heterarchical topological form able to display heterarchies.. Such a topology would be able to trace and make visible the

\footnotetext{
${ }^{4}$ A torus is able to depict interconnections of greater complexity than either "a plane" or "a sphere," whose topological characteristics are utilized so widely by the western rational tradition, because the solution to a mapping network on either a sphere or a plane utilizes a maximum of four- colours to cover it, whereas the solution to a mapping puzzle on a torus is seven.
} 
variety of "go-betweens," like honeybees, which relate human activity to insect activity to plant activity to the circularities of life cycle in climate change.

The 'pattern which connects', Bateson's phrase, is vital to our understanding of mutual causality. If he is correct, 'the patterns that disconnect,' that belong to the fast cycling communicative events of an ecosystem are equally important to understand. For it is these which will bring about ecosystem degradation - perhaps collapse - even before the slower biophysical effects of global warming become apparent.

\section{References}

Allen, T., \& Hoekstra, T. (1992). Toward a unified ecology: Complexity in ecological systems. New York: Columbia University Press.

Baluska, F. et al. (2006). Communication in plants: Neuronal aspects of plant life. Springer.

Bateson, Gregory. [1973] (2000). Steps to an Ecology of Mind. Chicago: Chicago University Press.

Bateson, Gregory, \& Mary Catherine, Bateson. (1987). Angels Fear: Towards an Epistemology of the Sacred. New York: Macmillan.

Berger, Kevin. (2007). "Who Killed the Honeybees?" Online: Encyclopedia Britannica, Advocacy for Animals, May 29, 2007. Retrieved September 17, 2007.

Grossman, D. (2004). Spring forward. Scientific American, 290(1), 85-91.

Harries-Jones, P. (1995). A recursive vision: Ecological understanding and gregory bateson. Toronto: University of Toronto Press.

Hoffmeyer, J. (1996). Signs of meaning in the universe. Bloomington: Indiana University Press.

Hoffmeyer, Jesper. (2008a). "Semiotic Scaffolding of Living Systems." In Marcello Barbieri (Ed.). Introduction to biosemiotics: The new biological synthesis. Springer Science pp. 149-166

Hoffmeyer, Jesper (Ed.). (2008b). A Legacy for Living Systems: Gregory Bateson as Precursor to Biosemiotics. Springer Science.

Intergovernmental Panel on Climate Change (IPCC). (2003). Science Statement on Current Understanding of the Processes Affecting Terrestrial Carbon Stocks and Human Influences on Them. Geneva, 21-23 July.

Intergovernmental Panel on Climate Change (IPCC). (2007). Fourth Assessment Report (AR4). Working Group II: Impacts, Adaptation and Vulnerability. Chapter 1 Section 1.3.5.1 ff.

McNeil, D. (2004). What's Going On with the Topology of Recursion? SEED Journal, 4.1, 2-37.

McNeil, Don. (2007). Going On with Systems. (Unpublished)

Maturana, H., \& Varela, F. J. (1998). The tree of knowledge. (revised edn). Boston, MA: Shambala Press.

Patten, B. C., \& Higashi, M. (1991). Network ecology: indirect determination of the life-environment relationships in ecosystems. In M. Higashi \& T. Platt (Eds.), Theoretical ecosystem ecology: The network perspective, pp. 288-351. London: Cambridge University Press.

Public Broadcasting System. (2007). "The Silence of the Bees," www.pbs.org/wnet/nature/episodes/ silence-of-the-bees. Retrieved October 28, 2007.

Sebeok, Thomas A. (1985). "Communication, Language and Speech: Evolutionary Considerations." in Is Earth a Living Organism? Proceedings of papers presented at the University of Massachusetts, Amherst, August 1-6, I985. National Audubon Society Expedition Institute, 1986. Paper No. 61.

UNITED States Department of Agriculture (USDA). (2007). Colony Collapse Disorder Action Plan. Online available in PDF (portable document format) at: http://www.ars.usda.gov/is/br/ccd/ccd actionplan.pdf ... Retrieved September 17, 2007. Questions and Answers: Colony Collapse Disorder. Online. www.ars.usda.gov/is/br/ccd/.... Retrieved September 17, 2007.

von Frisch, Karl. (1967). The Dance Language and Orientation of Bees. Cambridge: Belknap (Harvard University) Press. 